\title{
Earthquake Recurrence in Simulated Fault Systems
}

\author{
James H. Dieterich $^{1}$ and Keith B. Richards-Dinger ${ }^{1}$
}

\begin{abstract}
We employ a computationally efficient fault system earthquake simulator, RSQSim, to explore effects of earthquake nucleation and fault system geometry on earthquake occurrence. The simulations incorporate rate- and state-dependent friction, high-resolution representations of fault systems, and quasi-dynamic rupture propagation. Faults are represented as continuous planar surfaces, surfaces with a random fractal roughness, and discontinuous fractally segmented faults. Simulated earthquake catalogs have up to $10^{6}$ earthquakes that span a magnitude range from $\sim$ M4.5 to M8. The seismicity has strong temporal and spatial clustering in the form of foreshocks and aftershocks and occasional large-earthquake pairs. Fault system geometry plays the primary role in establishing the characteristics of stress evolution that control earthquake recurrence statistics. Empirical density distributions of earthquake recurrence times at a specific point on a fault depend strongly on magnitude and take a variety of complex forms that change with position within the fault system. Because fault system geometry is an observable that greatly impacts recurrence statistics, we propose using fault system earthquake simulators to define the empirical probability density distributions for use in regional assessments of earthquake probabilities.
\end{abstract}

Key words: Seismicity, earthquake simulations, earthquake recurrence, fault roughness.

\section{Introduction}

Many processes and interactions undoubtedly affect earthquake occurrence, and each may imprint its own signature on earthquake statistics. Heterogeneities in fault strength and stress conditions have a primary impact on the size/frequency distributions of earthquake ruptures (Rundle and KLein, 1993; STIRLing et al., 1996; Ben-Zion and Rice, 1997; Steacy and McCloskey, 1999). Heterogeneities may develop

1 Department of Earth Sciences, University of California, Riverside, CA 92521, USA. E-mail: Dieterichj@ucr.edu; keithrd@ ucr.edu as a remnant of dynamical complexity during earthquake rupture, from interactions during slip of geometrically complex fault systems, from heterogeneous material properties, and through external processes such as spatially non-uniform pore fluid pressure changes or off-fault yielding. Also, earthquake nucleation, because it determines both the time of occurrence and place of origin of earthquake ruptures, can strongly affect the space-time patterns of seismicity, particularly following stress perturbations. This study employs a fault system earthquake simulator to explore earthquake recurrence statistics. Our focus is on the possible imprinting of earthquake nucleation processes and fault system geometry on earthquake recurrence statistics.

The simulations incorporate time- and stressdependent earthquake nucleation as required by rateand state-dependent fault properties. The rate- and state-dependent constitutive formulation quantifies observed characteristic dependencies of sliding resistance on slip, sliding speed and contact time; and it provides a framework to unify observations of dynamic/static friction, displacement weakening at the onset of macroscopic slip, time-dependent healing, slip history dependence, and slip speed dependence (Dieterich, 1979, 1981; Ruina, 1983; Tullis, 1988; Marone, 1998). Laboratory studies of earthquake nucleation processes (DieTERICH and KILGORE, 1996) and studies of earthquake nucleation with rate- and state-dependent constitutive properties (DIETERICH, 1992, 1994; Rubin and Ampuero, 2005) indicate that nucleation processes are highly time- and stressdependent. Seismicity models that incorporate nucleation with rate- and state-dependent friction reproduce a variety of characteristics observed in seismicity data including foreshocks and aftershocks with Omori-type 
temporal clustering (DIETERICH, 1987, 2007; GOMBERG et al., 1997, 1998, 2000; BELARDINELli et al., 2003; ZIV and RuBin, 2003).

Fault system geometry is an obvious system-level structural heterogeneity that is both observable and persistent. Faults in nature are not geometrically flat surfaces, and they do not exist in isolation, but form branching structures and networks. These structural features are evident over a wide range of length scales. Individual faults exhibit roughness at all length scales that can be modeled as mated surfaces with random fractal topography (Scholz and Aviles, 1986; Power and Tullis, 1991; Sagy et al., 2007). Fault step-overs (Окиво and Акг, 1987) and fault system geometry (BonNET et al., 2001; BEN-Zion and SAmmis, 2003) also have fractal characteristics. Slip of faults with these features results in strong geometric incompatibilities and interactions that do not occur in planar fault models. For example, fault stepovers may break a fault into weakly connected segments that serve as persistent barriers that inhibit rupture propagation. Also, non-planarity of faults and fault branches gives rise to geometric incompatibilities that may similarly inhibit rupture growth. The fractal characteristics of faults and fault system geometry mean that these interactions operate over a wide range of length scales. Indeed Wesnousky (1994) proposes that individual faults making up a regional fault system have a strong tendency to generate characteristic earthquakes that essentially rupture an entire fault and that the characteristic Gutenberg-Richter earthquake magnitude-frequency distribution reflects the size distribution of faults in a region. This view is supported by idealized model studies (RundLe and KLein, 1993; StiRling et al., 1996; Ben-Zion and Rice, 1997; Steacy and McCloskey, 1999) but the issue remains an open question.

Previous modeling studies of earthquakes and slip in geometrically complex faults include investigation of slip of wavy faults (SAUCIER et al., 1992; Chester and Chester, 2000), slip through idealized fault bends (NIELSEN and KNOPOFF, 1998), rupture propagation into fault branches (OGLESBy et al., 2003; Fliss et al., 2005), and rupture jumps across gaps (Harris et al., 1991; Duan and Oglesby, 2006; Shaw and Dieterich, 2007). Seismicity simulations that implement region-specific models of fault systems (WARD, 1996, 2000; RUNDLE et al., 2004; Robinson and Benites, 1995) have demonstrated that plausible seismicity models can be implemented that replicate basic characteristics of regional seismicity. In this work we investigate the individual and combined effects of several of these forms of complexity on the recurrence statistics of earthquakes.

\section{Simulations}

This study employs synthetic catalogs with up to $10^{6}$ earthquakes that are generated using an efficient simulation procedure developed by DIETERICH (1995). The current model, RSQSim, uses 3-D boundary elements based on the solutions of either Okada (1992) or Meade (2007), and it accepts different modes of fault slip (normal, reverse, strike-slip) as well as mixed slip modes. In this study we examine only strike slip faults. With the current single processor version of the computer code, up to 30,000 elements are used to represent fault surfaces. This permits quite detailed 3-D representations of fault system geometry and fault interaction effects. In this study the simulations generally employ $1 \mathrm{~km} \times 1 \mathrm{~km}$ or $1.5 \mathrm{~km} \times$ $1.5 \mathrm{~km}$ elements, and seismicity catalogs span a magnitude range from roughly M 4-M 8. Although the simulations employ large-scale approximations and simplifications to achieve computational efficiency, comparisons with fully dynamic 3-D finite-element models described below indicate the calculations are quite accurate. Details of the computations together with an overview of the dynamic characteristics of individual events and characteristics of the synthetic catalogs are given by RichARDS-DingER and DIETERICH (in preparation). In the following we briefly describe the model computations and outline some important characteristics of the model.

RSQSim is based on a boundary element formulation whereby interactions among the fault elements are represented by an array of 3-D elastic dislocations, and stresses acting on the centers of the elements are 


$$
\begin{gathered}
\tau_{i}=K_{i j}^{\tau} \delta_{j}+\tau_{i}^{\text {tect }} \\
\sigma_{i}=K_{i j}^{\sigma} \delta_{j}+\sigma_{i}^{\text {tect }},
\end{gathered}
$$

where $i$ and $j$ run from 1 to $N$, the total number of fault elements; $\tau_{i}$ and $\sigma_{i}$ are the shear stress in the directions of slip and fault-normal stress on the $i$ th element, respectively; the two $K_{i j}$ are interaction matrices derived from elastic dislocation solutions; $\delta_{j}$ is slip of fault element $j ; \tau_{i}^{\text {tect }}$ and $\sigma_{i}^{\text {tect }}$ represent stresses applied to the $i$ th element by sources external to the fault system (such as far field tectonic motions); and the summation convention applies to repeated indices. The code uses full 3-D boundary element representations and can employ rectangular (OKADA, 1992) or triangular (MEADE, 2007) fault elements.

The model employs a rate- and state-dependent formulation for sliding resistance (DIETERICH, 1979, 1981; RuinA, 1983; Rice, 1983):

$$
\tau=\sigma\left[\mu_{0}+a \ln \left(\frac{\dot{\delta}}{\dot{\delta}^{*}}\right)+b \ln \left(\frac{\theta}{\theta^{*}}\right)\right],
$$

where $\mu_{0}, a$, and $b$ are experimentally determined constants; $\dot{\delta}$ is sliding speed; $\theta$ is a state variable that evolves with time, slip, and normal stress history; and $\dot{\delta}^{*}$ and $\theta^{*}$ are normalizing constants. In the simulations fault strength is fully coupled to normal stress changes through the coefficient of friction and through $\theta$, which evolves with changes of normal stress as given by LinKeR and DieTERICH (1992):

$$
\dot{\theta}=1-\frac{\dot{\delta} \theta}{D_{c}}-\frac{\alpha \theta \dot{\sigma}}{b \sigma} .
$$

At constant normal stress, the evolution of $\theta$ takes place over a characteristic sliding distance $D_{c}$, and for a constant sliding speed $\dot{\delta}$ will approach a steadystate of $\theta_{\text {ss }}=D_{c} / \dot{\delta}$. See Marone (1998) and DieteRICH (2007) for detailed reviews of rate- and statedependent friction and a discussion of applications.

A central feature of the method is the use of event-driven computational steps as opposed to timestepping at closely spaced intervals (DiETERICH, 1995). The cycle of stress accumulation and earthquake slip at each fault segment is separated into three distinct phases designated as sliding states 0,1 , and 2 that are based on more detailed models with rate- and state-dependent fault constitutive properties. Previously Dieterich (1995) and ZIV and RubiN (2003) employed this three-state approach to model foreshock and aftershock processes. A fault element is at state 0 if stress is below the steady-state friction, as defined by rate- and state-dependent friction. In the model this condition is approximated as a fully locked element in which the fault strengthens as the frictional state-variable $\theta$ increases with time, e.g., $\theta=\theta_{0}+t$ at constant normal stress, but modified by effects arising from normal stress changes using the LINKER and DiETERICH (1992) formulation.

The transition to sliding state 1 occurs when the stress exceeds the steady-state friction. During state 1, conditions have not yet been met for unstable slip, although the fault progressively weakens as described by rate- and state-dependent fault constitutive properties. Analytic solutions for nucleation of unstable slip (DIETERICH, 1992) generalized for varying normal stress (DIETERICH, 2007; RichaRDS-DingeR and DiETERICH, in preparation), together with stressing rate determine the transition time to state 2 , which is earthquake slip. At tectonic stressing rates, earthquake nucleation typically requires a year or more, however during earthquake slip the high stressing rates at the rupture front compress the duration of state 1 to a fraction of a second. Hence, during an earthquake rupture, state 1 in effect forms a process zone at the rupture front, where time-dependent breakdown of fault strength occurs. The slip during nucleation is negligible compared to coseismic earthquake slip and is therefore ignored for purposes of computing stress changes on other elements.

During earthquake slip (state 2), the model employs a quasi-dynamical representation of the gross dynamics of the earthquake source based on the relationship for elastic shear impedance together with the local dynamic driving stress. From the shear impedance relation (BRUNE, 1970) the fault slip rate is

$$
\dot{\delta}_{j}^{\mathrm{EQ}}=\frac{2 \beta \Delta \tau_{j}}{G},
$$

where the driving stress $\Delta \tau_{j}$ is the difference between the stress at the initiation of slip and the sliding friction at element $j ; \beta$ is the shear-wave speed; and $G$ 
is the shear modulus. This provides a first-order representation of dynamical time scales and slip rates for the coseismic portion of the earthquake simulations. In the simulations described here a single rupture slip speed was used that is based on average values of $\Delta \tau_{j}$. An element ceases to slip and reverts to state 0 when the stress decreases to some specified stress determined by the sliding friction (with inertial overshoot of stress to levels less than the sliding friction as an adjustable model parameter).

The computational efficiency of the model is obtained from the use of event-driven computational steps, use of analytic nucleation solutions, and specification of earthquake slip speed from the shear impedance relation. Determination of the sliding state changes requires computation of the stress state as a function of time at each fault element. Note that stressing rates are constant between state changes, and the change of stressing rate at any element $i$ resulting from the initiation or termination of earthquake slip at element $j$ is given by

$$
\begin{aligned}
\dot{\tau}_{i} & =\dot{\tau}_{i} \pm K_{i j}^{\tau} \dot{\delta}_{j}^{\mathrm{EQ}} \\
\dot{\sigma}_{i} & =\dot{\sigma}_{i} \pm K_{i j}^{\sigma} \dot{\delta}_{j}^{\mathrm{EQ}} \text { (no summation), }
\end{aligned}
$$

where the + and - refer to $1 \rightarrow 2$ and $2 \rightarrow 0$ transitions on element $j$, respectively. Hence, these state transition events require only one multiply and add operation at each element to update stressing rates everywhere in the model (no system-scale updates are required for the $0 \rightarrow 1$ transition). These changes to the stressing rates are applied instantaneously to all patches in the model (but note that the stresses themselves do not change discontinuously). A possible improvement to the model, with which we plan to experiment in the future, would be to delay the changes by a suitable wave propagation speed. Because the transition times depend only on initial conditions and stressing rates, computation proceeds in steps that mark the transition from one sliding state to the next without calculation of intermediate steps. This approach completely avoids computationally intensive solutions of systems of equations at closely spaced time intervals. Computation time for an earthquake event of some fixed size, embedded in a model with $N$ fault elements, scales approximately by $N^{1}$.
For this study, stressing-rate boundary conditions drive fault slip and are set using the back-slip method (Savage, 1983; King and Bowman, 2003). With this method, the stressing rates acting on individual fault elements are found through a one-time calculation in which all fault elements slide backwards at specified long-term geologic rates. This insures that long-term stressing rates are consistent with observed slip rates. The method provides a lumped representation of all stressing sources, including tectonic stressing and stress transfer from off-fault yielding, consistent with prescribed/observed long-term fault slip rates. A characteristic of backslip stressing is that regions of uniform long-term slip rate require non-uniform stressing rates-stressing rates vary most strongly at the ends and bottom of the fault.

\section{Model Characteristics}

Except as noted, the simulations employ fault models with uniform initial normal stresses of $150 \mathrm{MPa}$ and uniform constitutive properties of $a=0.012, b=0.015, \mu_{0}=0.6$, and $D_{c}=10^{-5} \mathrm{~m}$; these are typical laboratory values (DIETERICH, 2007). Three fault surface geometries are employed in isolation or as components of fault systems: (1) continuous planar surfaces, (2) continuous surfaces with random fractal roughness, and (3) discontinuous fractally segmented faults in which segment boundaries are delineated by fault step-overs.

The fractally rough surfaces are generated using the method of random mid-point displacement (FourNIER et al., 1982) whereby the fault surface is repeatedly divided and the midpoints of the new divisions are randomly displaced by a normally distributed random variable with a standard deviation given by

$$
y=\beta l^{H},
$$

where $l$ is the current subdivision length; the factor $\beta$ is the rms slope at a reference division length $l=1$; and the exponent $H$ has values $0-1$. In the following we use $H=1$, which generates self-similar profiles. At large scales (wavelengths $>1 \mathrm{~km}$ ) real faults have discernible roughness indicating 
values of $\beta$ approximately in the range $0.01-0.05$ (Dieterich and SMith, 2009).

For fractally segmented faults we again employ the random mid-point displacement method used to generate the fractally rough faults but with two modifications. First, during the subdivision process every segment is not necessarily subdivided; instead there is some probability for a segment to be subdivided (the probability is 0.85 for the models used in this study). Second, the resulting points are taken as the centers of planar segments, all of which are parallel to the overall fault (rather than as the vertices of a continuous triangulated surface). This leads to a fractal (power-law) distribution of segment sizes and offsets between them. Any segments larger than the desired patch size are subdivided down to the desired patch size but with all these patches being coplanar and continuous.

Examples of isolated faults with fractal roughness and fractal segmentation are shown in Fig. 1. The slip events that are shown in Fig. 1 are taken from simulations of 500,000 earthquake events on those faults. Compared to planar faults, which tend to have smooth displacement profiles along the rupture, the somewhat patchy slip for the events in Fig. 1 appears to be characteristic of the fractal faults. Larger earthquake ruptures on faults with fractal roughness break through both releasing and constraining bends, however smaller earthquake ruptures tend to occur preferentially along constraining fault bends.

The simulations produce a range of rupture characteristics that are comparable to those obtained in detailed fully dynamical calculations. Rupture speeds for large earthquakes in these simulations generally range $2.0-2.4 \mathrm{~km} / \mathrm{s}$, which is reasonable given the implied shear-wave speed of $3.0 \mathrm{~km} / \mathrm{s}$ used to set slip speed. Rupture growth and slip can be crack-like, or consist of a narrow slip-pulse (HEATON, 1990). Factors favoring crack-like behavior in the simulations are relatively smooth initial stresses and weak healing (re-strengthening of the fault) following termination of slip, while slip-pulse behavior arises with heterogeneous initial stresses and strong fault healing following rupture termination. This behavior is consistent with fully dynamical rupture simulations (Beroza and Mikumo, 1996; Zheng and Rice, 1998). In our simulations, healing is set by the rate-state

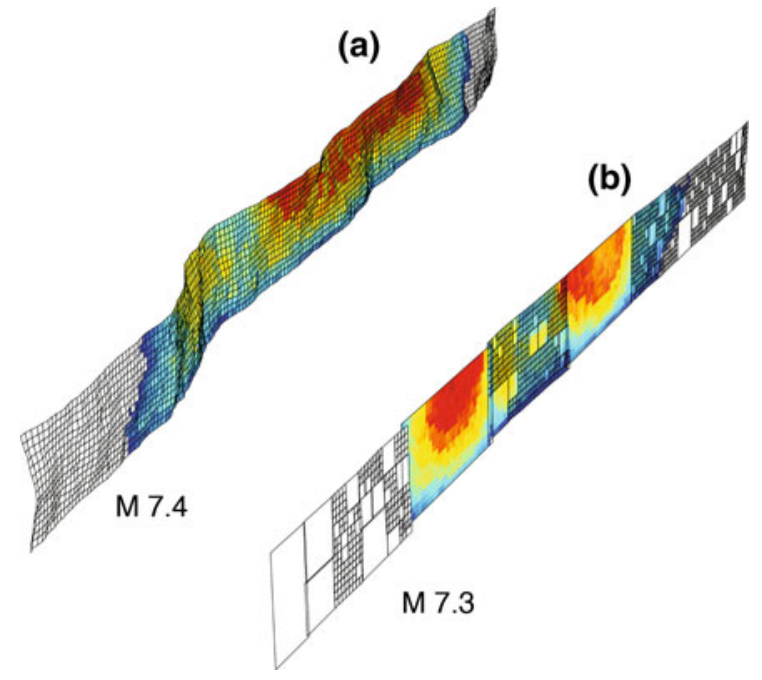

Figure 1

Coseismic slip on isolated strike-slip faults with a fractal roughness and $\mathbf{b}$ fractal segmentation. The color scale indicates slip in a single large earthquake that occurred in simulations with 500,000 events. The rough fault uses an exceptionally large amplitude factor $(\beta=0.10)$ to illustrate the character of the fractal roughness. With the segmented fault only the segment boundaries are shownindividual segments are made up of $1 \mathrm{~km} \times 1 \mathrm{~km}$ elements. The amplitude factor for the segmented fault is $\beta=0.04$. Both fault models have 3,015 elements.

frictional properties and by a dynamic stress overshoot parameter that determines the shear stress at the termination of slip relative to the sliding friction. During an earthquake, if sliding stops at stresses that are sufficiently below the sliding friction, then healing outpaces re-stressing from continuing slip on adjacent regions of the fault. This inhibits renewed or continuing slip and leads to pulse-like ruptures. Conversely, if sliding stops at or only slightly below the sliding friction, then continuing slip on adjacent regions of the fault can immediately trigger renewed sliding before healing can occur. This effect favors on- and off-switching of slip, which approximates continuous slip over broad regions at slower slip speeds, which is characteristic of crack-like ruptures.

Although the simulations employ approximations of the earthquake rupture processes to achieve computational efficiency, we believe those approximations do not seriously distort the model results. The key performance measure for earthquake rupture calculations in seismicity simulations is the accuracy with which the calculations predict (a) the size of 

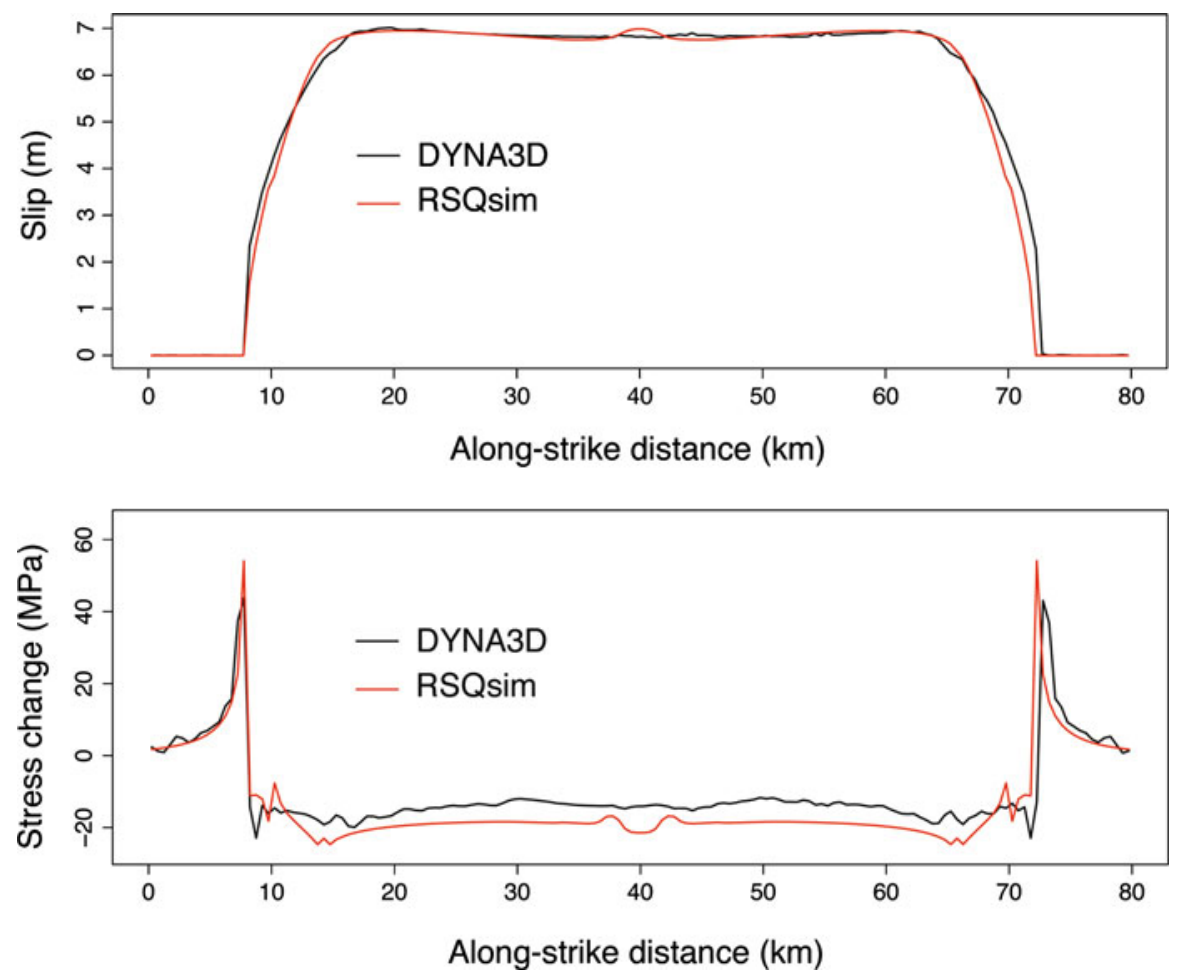

Figure 2

Comparison of slip and shear stress change from 3-D bilateral rupture simulations on a planar strike slip fault with RSQSim and DYNA3D (Richards-Dinger et al., in preparation). The total rupture length is $64 \mathrm{~km}$ and slip extends from the surface to a depth of $8 \mathrm{~km}$. The computations employ $500 \mathrm{~m} \times 500 \mathrm{~m}$ fault elements.

earthquake rupture given a stress state at the initiation of an earthquake, and (b) the slip distribution in that rupture, which determines the details of the stress state in the model following an earthquake (and therefore subsequent earthquake history). In collaboration with our colleague David Oglesby and with the assistance of student interns Christine Burrill and Jennifer Stevens we have undertaken a program of tests that compare single-event RSQSim simulations with detailed fully dynamic finite element calculations (RICHARDS-DingER et al., in preparation). Figure 2 shows one in a series of comparisons of RSQSim with DYNA3D, a fully dynamic 3-D finite-element model. DYNA3D employs slip-weakening friction at the onset of earthquake slip with specified static and sliding friction. Hence, it was necessary to match the rate-state friction parameters and initial conditions as closely as possible to the friction, stress, and slip-weakening conditions in DYNA3D. The example in Fig. 2 is for a bilateral rupture on a strike-slip fault with uniform initial stress and sliding resistance during earthquake slip. Other comparisons of simple bilateral and unilateral ruptures under conditions of uniform initial stress give similar results.

Similarly, models with heterogeneous stresses are in good agreement. This includes models with heterogeneous normal stress that produce highly complex rupture histories with heterogeneous earthquake stress drop. The principal mismatch between the simulation methods occurred in a case in which initial shear stress was smoothly tapered over a distance of $20 \mathrm{~km}$ to progressively impede rupture propagation. Both models produced very similar slip and stress patterns, however the fully dynamic rupture penetrated about $3 \mathrm{~km}$ farther into the low stress region than the quasi-dynamic rupture, resulting in final rupture lengths of 57 and $60 \mathrm{~km}$ for RSQSim and DYNA3D, respectively. The somewhat longer rupture obtained with the dynamic finite-element model may arise from dynamic stress effects, which are not represented in RSQSim. Alternatively it may be caused by differences in the failure laws that 

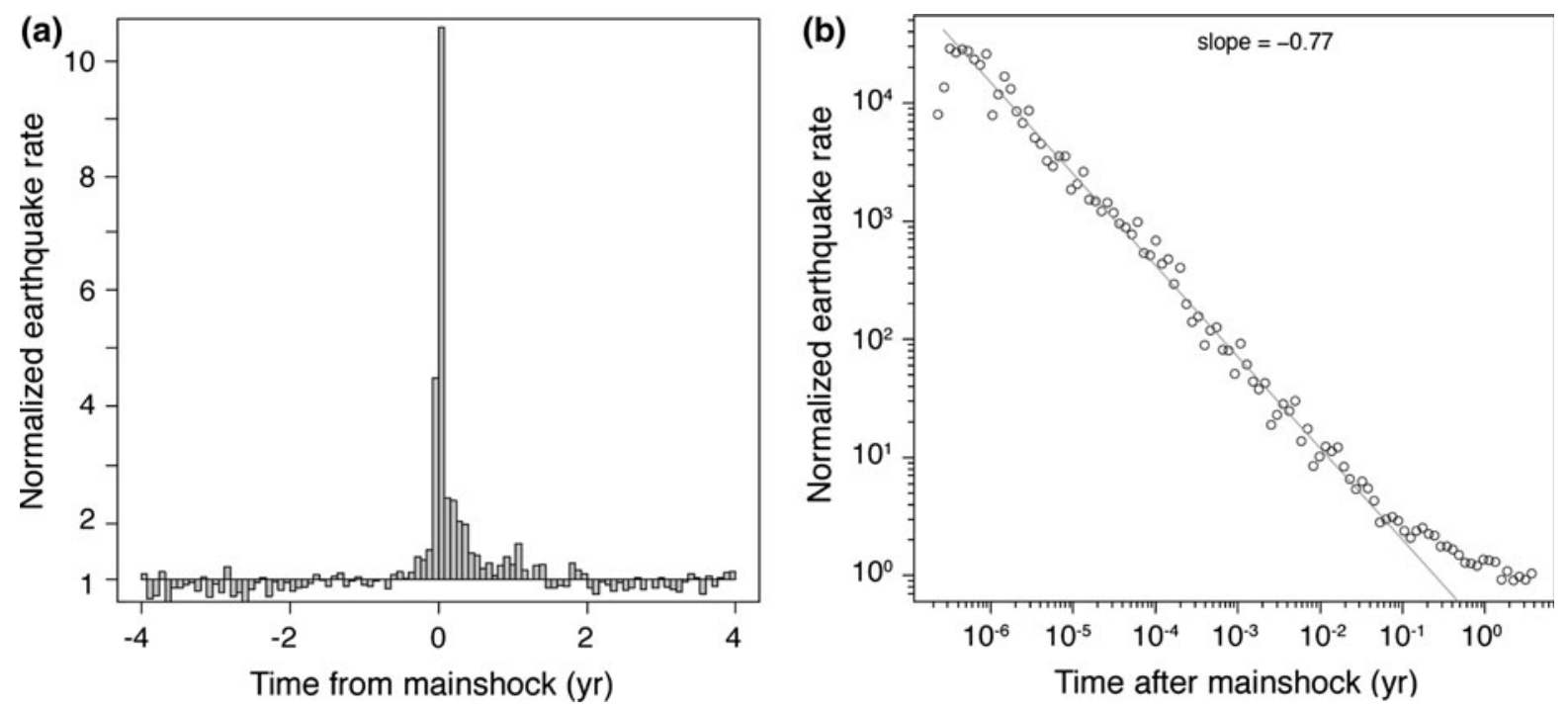

Figure 3

Foreshocks and aftershocks from a simulation of 500,000 earthquakes spanning 16,370 years. The simulations use the smooth fault version of the idealized fault system model described below with $67601 \mathrm{~km} \times 1 \mathrm{~km}$ elements. These records are composite plots formed by stacking the rate of seismic activity relative to main-shock times. Main shocks are $6<M<7$ separated by at least 4 years from any other events $M>6$. Earthquake rates are normalized by the average background rate. The same data set is used in $\mathbf{a}, \mathbf{b}$. a Composite plot of showing foreshocks and aftershocks relative to main-shock time. b Characteristic decay of aftershocks by $t^{-p}$, with $p=0.77$. Foreshocks (not shown) have a similar power-law decay by time before the main shock with $p=0.92$.

control rupture growth used in the two codes. The direct rate strengthening effect with rate- and statedependent friction law used in RSQSim results in transient rate-strengthening at the rupture front that tends to impede rupture growth relative to the rateindependent slip weakening law in DYNA3D. Additional tests are underway.

The simulations produce clustered seismicity that includes foreshocks, aftershocks and occasional large earthquake clusters. Composite seismic histories constructed by stacking seismic activity relative to main-shock occurrence times (Fig. 3) replicate the Omori aftershock decay of aftershock rates by $t^{-p}$ with $p \sim 0.8$, and foreshocks have Omori-like dependence of foreshock rates by time before the main shock with $p \sim 0.9$. Because clusters of large events sometimes occur that produce overlapping aftershock sequences, the stacking procedure used to construct the record in Fig. 3 employed an added constraint that rejected sequences if more than one earthquake $M \geq M_{\min }$ occurred in a \pm 4 year interval. The example presented in Fig. 3 was obtained with the smooth fault section version of an idealized fault system described below (e.g., Fig. 5) that consisted of
13 fault sections of various lengths. Clustering in systems with fractal roughness and fractal segmentation is somewhat greater than simulations with planar faults. Previously, Dieterich (1995) showed that productivity of foreshocks and aftershocks (i.e., the ratios of the numbers of foreshocks and aftershocks to main shocks in a magnitude interval) is controlled by the product $a \sigma$, where $a$ is the rate-state parameter appearing in Eq. 3 and $\sigma$ is normal stress.

The magnitude frequency distributions of simulated earthquakes for isolated planar faults consistently follow a power law up to about M6.0, together with a pronounced peak that marks characteristic earthquakes that rupture the entire fault. There is a very pronounced deficiency of events between $M 6.0$ and M7.4. The upper limit of earthquake magnitude for the power-law portion of the distributions corresponds to rupture dimensions of about $10 \mathrm{~km}$ (compared to a vertical fault dimension of $15 \mathrm{~km}$ ). The characteristic earthquake behavior reflects a strong tendency of earthquake ruptures that reach dimensions greater than about $10 \mathrm{~km}$ to continue propagating to the limits of the model. Following such end-to-end ruptures the stress conditions 
are reset to a similar average value, which in turn results in highly periodic recurrence of the largest earthquakes.

The principal difference seen in simulations with fractally rough faults is slight enrichment of earthquakes in the magnitude interval between the powerlaw region and the characteristic earthquakes. However, there remains a strong deficiency of events in this range, even using an extreme roughness with $\beta=0.10$. The use of fractal segmentation has a significantly stronger impact on filling the deficiency between the power-law region and the characteristic earthquakes. Also, as the amplitude of fractal offsets increases, the frequency of characteristic earthquakes decreases-and their recurrence becomes less periodic. At the extreme of fractal segmentation that we studied ( $\beta=0.04)$ no end-to-end ruptures occurred in a simulation of $10^{6}$ events.

\section{Recurrence Distributions}

We have assembled distributions of the time intervals separating earthquakes above a minimum magnitude $M_{\min }$ that affect the same point on a fault. Distributions of this type reflect local characteristics of fault stressing and failure processes and form the basis for estimating conditional time-dependent probabilities along a section of a fault given the time of the previous earthquake. The density distributions are constructed by first binning the recurrence intervals for individual fault elements then summing the binned data with the data from other elements that make up a designated fault section. Fault sections consist of many elements (320 to $>1,000)$ and represent distinct structural components such as an isolated fault or the portion of a fault that lies between two branching points in a fault system. To construct the distributions, sequences of $5 \times 10^{5}$ to $10^{6}$ earthquakes were simulated representing records of extending to about 35,000 years at fault slip rates of $25 \mathrm{~mm} /$ year.

Models of seismicity on single isolated strike-slip faults employ a planar fault surface, a fault with random fractal roughness, and a fault with random fractal segmentation. In each case the fault dimensions are $201 \mathrm{~km}$ long, $15 \mathrm{~km}$ deep and consist of
3,015 elements with nominal dimensions of $1 \mathrm{~km}^{2}$. The long-term slip rate is $25 \mathrm{~mm} /$ year. Because the effect of fractal roughness on the recurrence statistic is rather weak, results are shown only for the extreme case with $\beta=0.10$. The amplitude parameters for faults with fractal segmentation use $\beta=0.02,0.03$, and 0.04. In all non-planar models $H=1.0$.

The recurrence distributions for each of the single fault models (Fig. 4) differ in minor details, nonetheless all share several common characteristics. (1) The distributions change with earthquake magnitude. (2) There is a very narrow peak at the shortest intervals (0-12 years). This peak is strongest for the smallest magnitude threshold $M_{\text {min }} \geq 5$ and decreases as $M_{\text {min }}$ increases. When examined in detail, the earthquakes in this interval are found to represent foreshocks, aftershocks, and regions of overlapping slip for earthquake pairs. Within this 0-12 year interval the recurrence rates have the characteristic Omori decay by $t^{-p}$ shown in Fig. 3. (3) There is a pronounced peak of recurrence times around 150-200 years, indicating a strong periodic component to recurrence. This peak appears in all the distributions using different $M_{\min }$, but it results from periodicity of large characteristic earthquakes that rupture the most or all of the fault. (4) The distributions that employ smaller magnitude thresholds $M_{\min } \geq 5.0$ are somewhat complex with a more-orless uniform density of recurrence times prior to the characteristic earthquake peak. The close similarity of the distributions $M_{\min } \geq 6.0$ and $M_{\min } \geq 7.0$ reflect the relative dearth of earthquakes $6 \leq M<7$ compared to characteristic earthquakes $M \geq 7.0$ that rupture most or all of the fault.

The distributions obtained with the isolated planar fault and with faults which have fractal roughness are quite similar. The principal difference in the density distributions is a progressive shifting of the characteristic earthquake peak to shorter times as roughness increases. The peak in the distributions of recurrence time for the planar fault is $\approx 190$ years compared to $\approx 150$ years for a very rough fault with $\beta=0.10$. Also, the longest recurrence interval for the planar fault is approximately 220 years, while the simulations with fractal roughness have a continuing low incidence of recurrence exceeding 400 years. These differences arise because fractal roughness introduces 
Magnitude of prior event $\mathrm{M}_{1} \geq 5.0, \quad \mathrm{M}_{2} \geq 5.0$
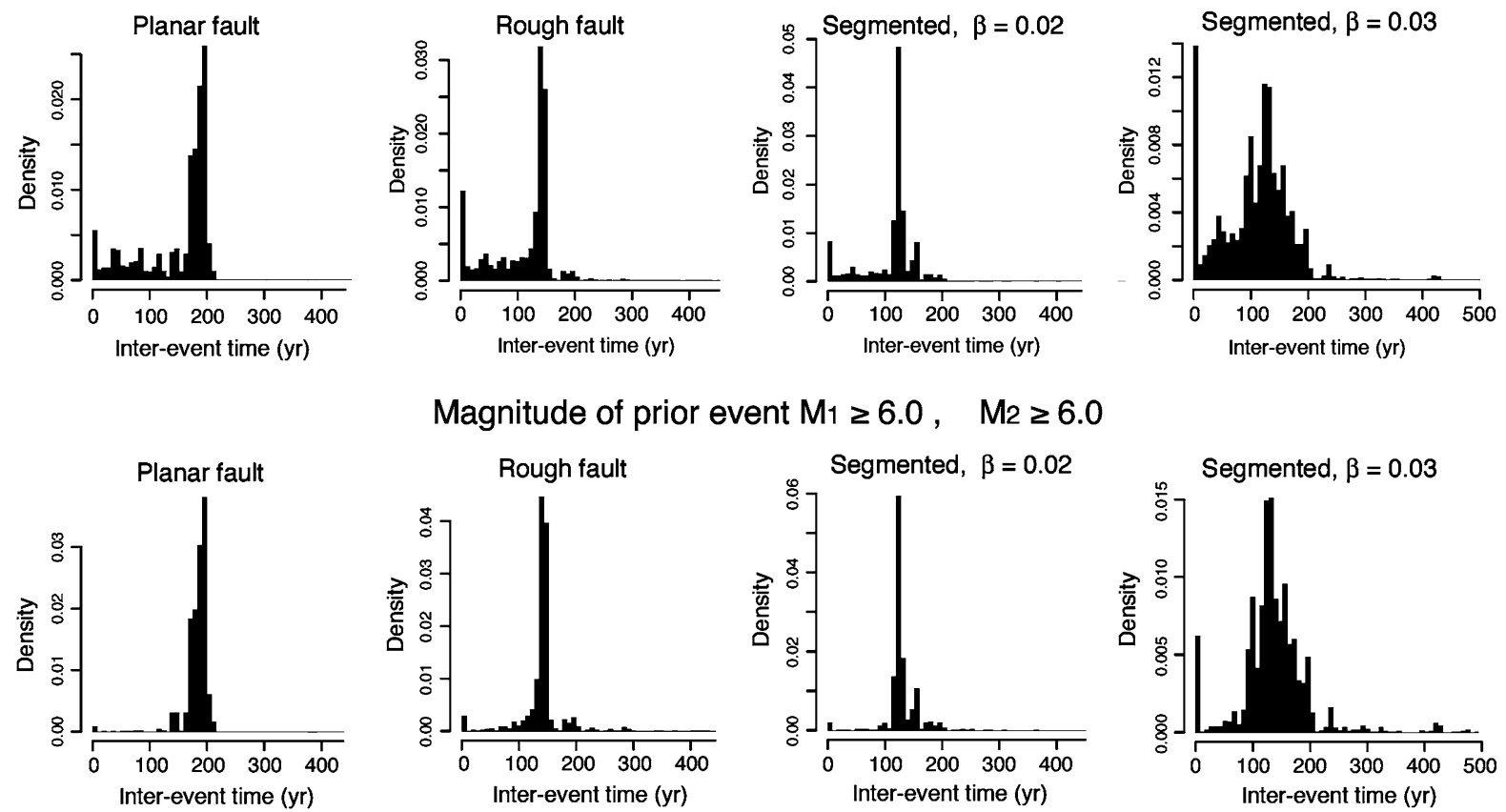

Magnitude of prior event $M_{1} \geq 6.0, \quad M_{2} \geq 6.0$
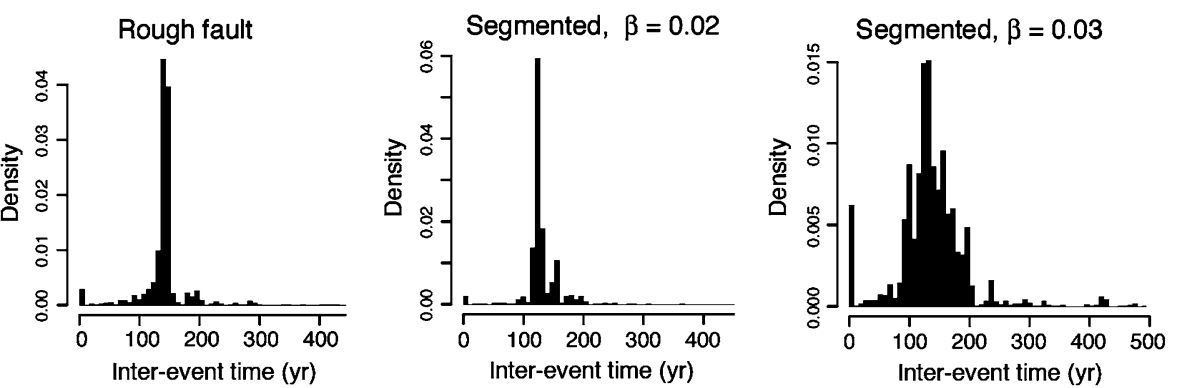

Magnitude of prior event $\mathrm{M}_{1} \geq 7.0, \quad \mathrm{M} 2 \geq 7.0$
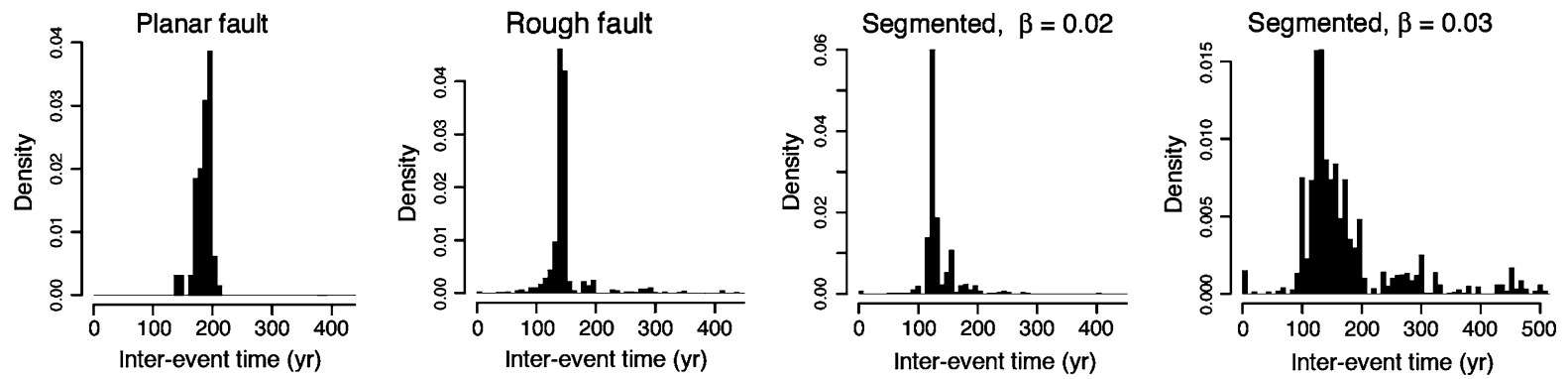

Figure 4

Density distributions of recurrence times for single isolated faults. The distributions give the density of inter-event times between successive earthquake pairs above the minimum magnitudes M 1 and M 2 for the first and second events, respectively, that define a pair.

weak barriers that inhibit slip and sometimes interrupt full growth of large earthquakes over the entire fault. This results in less slip and shorter recurrence time (on average) for large characteristic earthquakes, and occasionally skipped recurrence cycles.

Segmentation more strongly alters the distributions than fault roughness. Segmented faults with $\beta \leq 0.02$ produce distributions that are nearly identical to the rough fault with $\beta=0.10$. However, at $\beta \geq 0.03$ fractal segmentation significantly broadens the quasi-periodic peaks in the recurrence distributions. For example using $M_{\min } \geq 7.0$ the standard deviations for recurrence with a planar fault and a fault with fractal roughness $(\beta=0.10)$ are 14 and 45 year, respectively; compared to standard deviations of 28, 111, and 296 year for segmented faults with $\beta=0.02,0.03$, and 0.04 , respectively. With increasing separation across segmentation boundaries (increasing $\beta$ ) the rate of end-to-end earthquake ruptures decreases. At $\beta \geq 0.04$, no end-to-end earthquake ruptures occurred in a simulation with 200,000 events, although a broad peak in the distributions persists.

Simulations with a more complex but highly idealized fault system model (Fig. 5) were conducted to examine the effects of the geometric component of 
fault interactions on recurrence statistics. In the following we use the term fault section to indicate the portion of an individual fault that lies between branch points in the fault system. The model consists of parallel and branching faults and incorporates a variety of configurations, fault section lengths, and slip rates (see Fig. 5). The model consists of 6,760 elements with nominal dimensions of $1.5 \mathrm{~km} \times$ $1.5 \mathrm{~km}$. In addition to the model with smooth fault sections, several versions were implemented with fractal roughness and fractal segmentation using a range of values of $\beta$. To test for possible model resolution effects, the smooth fault version also used $1 \mathrm{~km} \times 1 \mathrm{~km}$ and $3 \mathrm{~km} \times 3 \mathrm{~km}$ patches. One simulation was carried out with a different set of ratestate friction parameters $(a=0.007$ and $b=0.010)$.

Representative density distributions for earthquake recurrence on the smooth fault version of the fault system model version are shown in Fig. 5. The characteristic features of distributions for single isolated faults described above are also seen in the density distributions for the fault system (peak at short times, magnitude dependence, quasi-periodicity, complexity at small $M_{\text {min }}$ ). Also it is very evident that the density distributions change significantly with position within the fault system and have a greater variety of forms than the isolated fault simulations. For example, at $M_{\min } \geq 5$ the forms include an approximately monotonic decay of density with time (Fig. 5, section 7), long interval of constant density followed by comparably long tail with decaying density (Fig. 5, section 4), and multipeaked distributions (Fig. 5, sections 6, 9 and 10).

At larger magnitudes $\left(M_{\min } \geq 6, M_{\min } \geq 7\right.$, and $\left.M_{\text {min }} \geq 7.5\right)$ the distributions maintain strong positional dependencies, but generally take somewhat simpler forms. Of the 13 fault sections in the model, all but three density distributions (including sections 4 and 6 in Fig. 5) have a single well-defined peak indicating quasi-periodicity of recurrence times. However, there are large differences in the shapes and widths of the peaks. Compared to the isolated fault models, the distributions generally have much larger spreads of recurrence times than the isolated fault models, which is expected given the increased complexity of interactions that determine the stressing history of the faults.
Figure 5

Idealized strike-slip fault system and density distributions for recurrence for representative fault sections (section numbers are given in the top panel as circled numbers, e.g., (4)). The faults extend from the surface to a depth of $15 \mathrm{~km}$. Motion on the fault is right lateral and the slip rates for each fault section are indicated in the top panel. The probability density distributions are for the smooth fault version of the model. See Fig. 6 for comparisons with models that employ fractal roughness and fractal segmentation of the fault sections.

We attempted to fit a variety of analytic probability distributions (e.g., Weibull, log-normal, and Brownian passage time) to these recurrence distributions. None of these analytic forms fit any of the entire (i.e., including the short-time power-law behavior) empirical distributions. If the short-time part of the empirical distributions is removed (or, equivalently, we attempt to fit the empirical distributions with the sum of a power law and one of the aforementioned analytic distributions) then a few of the distributions can be fit reasonably well by one or the other of the analytic forms, however most cannot.

Comparisons of distributions of interevent times for smooth fault sections with those using fractal roughness and fractal segmentation are summarized in Fig. 6. To facilitate comparisons we use cumulative distributions, which permits results to be plotted together. The surfaces with fractal roughness (with $\beta$ up to 0.10 ) closely follow those with smooth surfaces. Indeed, the differences between the rough and smooth surfaces are smaller with the fault system model than with the isolated fault models. This perhaps indicates that stress interactions that are linked to system geometry override local fault geometry in setting recurrence characteristics. Similarly, weak to moderately segmented fault surfaces $(\beta \leq 0.03)$ produce distributions that are very similar to the distributions with rough surfaces and are not plotted. The distributions with strongly segmented faults ( $\beta=0.04$ ), which are shown in Fig. 6, diverge somewhat from the other distributions, but generally retain the shapes of the other distributions. The single exception to this is at fault section 4 , which is a short section with low slip rate that branches from longer fault sections with higher slip rates. Because large earthquakes have longer rupture lengths than the length section 4 , of necessity such earthquakes on 


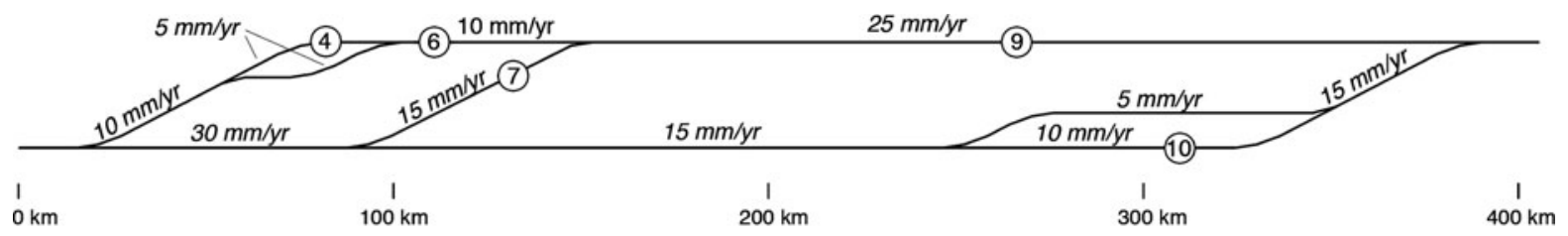

Probability density - smooth fault sections
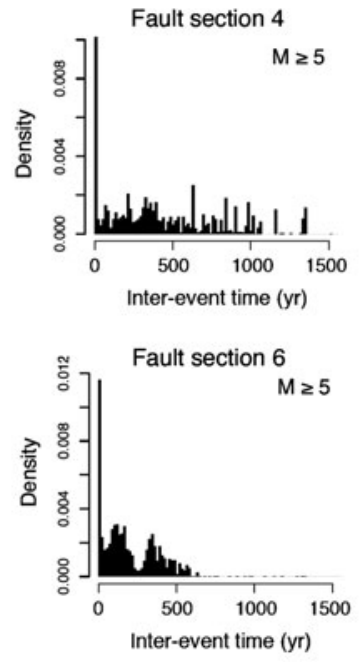

Fault section 7

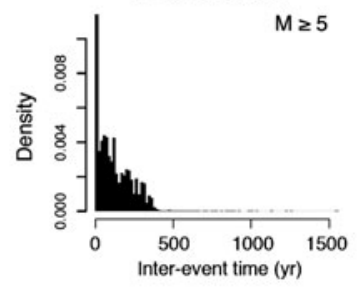

Fault section 9

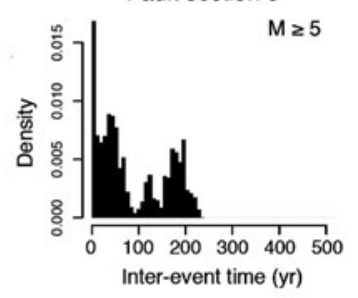

Fault section 10

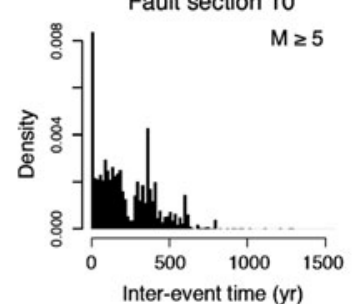

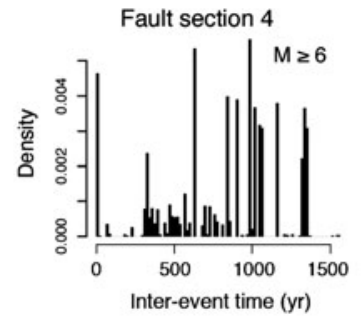
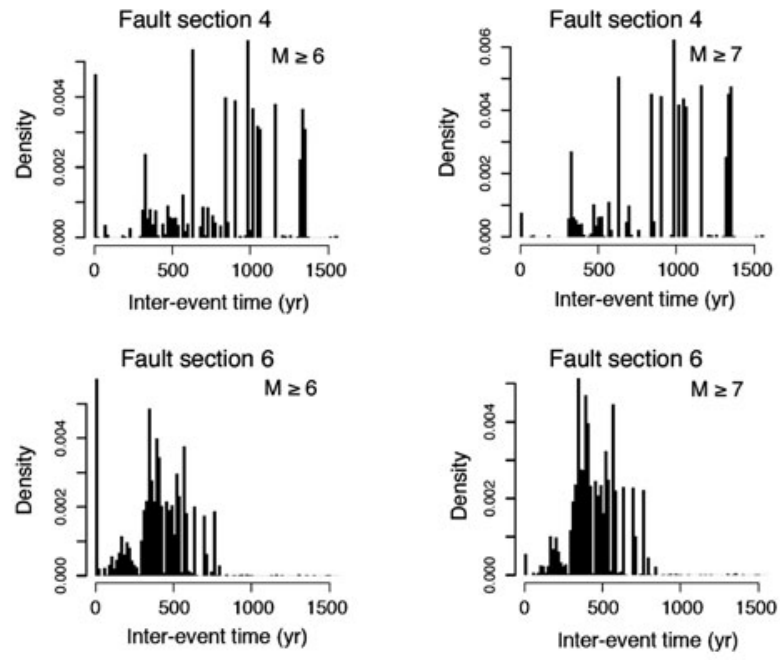

Fault section 7
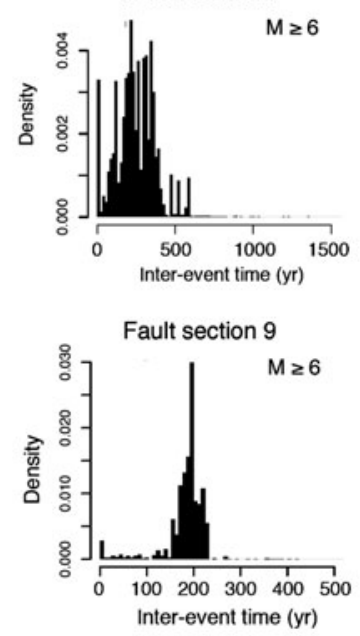

Fault section 10

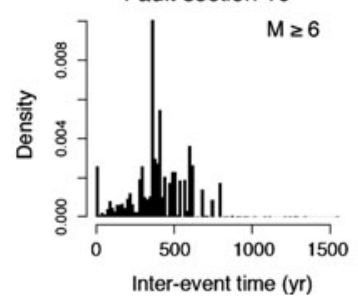

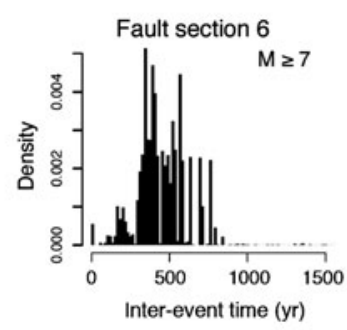

Fault section 7

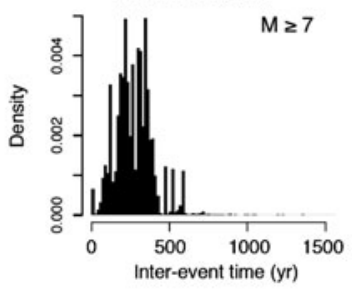

Fault section 9

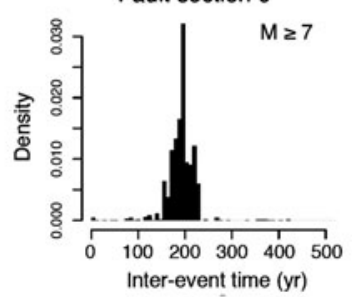

Fault section 10

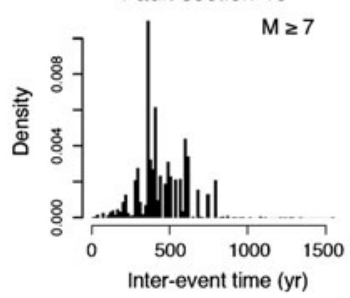




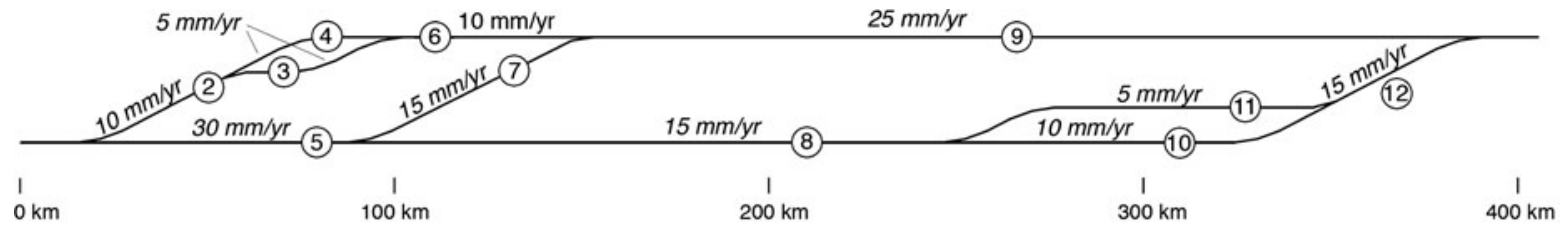

\section{Cumulative distributions}

\section{Smooth fault \\ Fractal rough \\ Fractal segmentation}
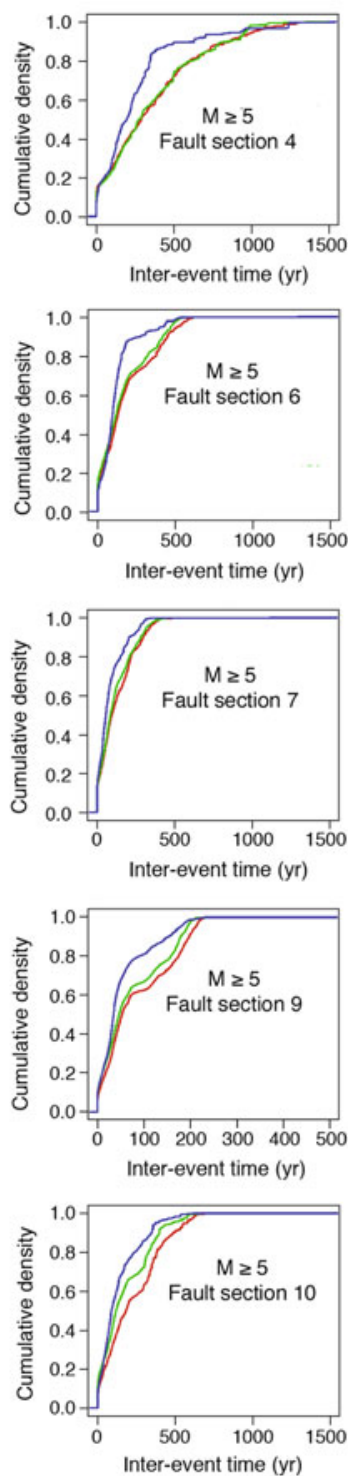
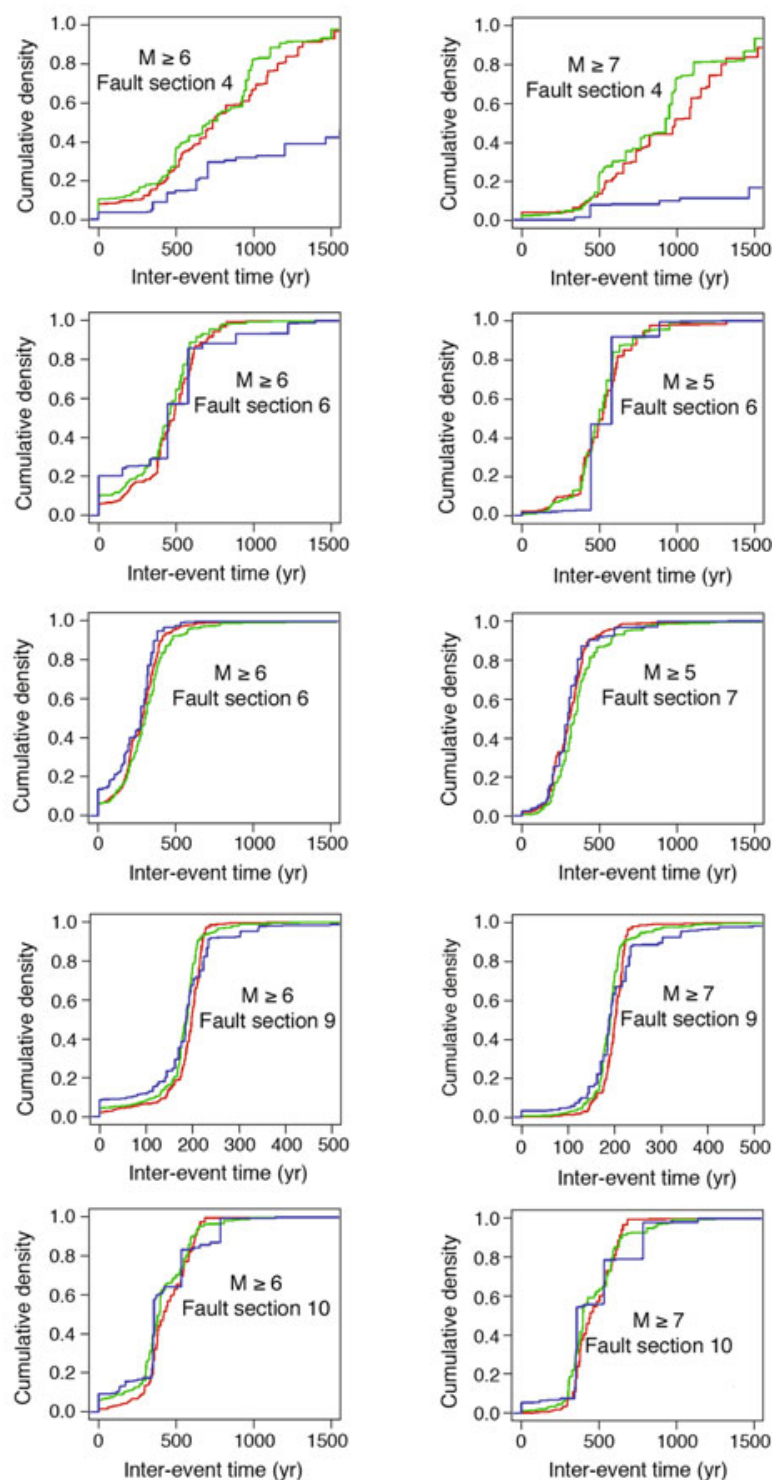

Figure 6

Cumulative distributions of recurrence times for earthquakes of various magnitudes on selected sections of an idealized fault system (upper panel) with three different forms of small-scale geometry: Smooth fault sections (red), fractal roughness with $\beta=0.1$ (green), and fractal segmentation with $\beta=0.04$ (blue). 
Table 1

Clustering of earthquakes $M \geq 7$ in fault system simulations

\begin{tabular}{llllll}
\hline Model & Total number of events & Number $(M \geq 7)$ & Single events & Double events & Triple events \\
\hline Planar faults & 299,000 & 196 & 130 & 27.5 & 3.6 \\
Fractal roughness $\beta=0.1$ & 377,000 & 237 & 152 & 35.8 & 4.6 \\
Fractal segmentation $\beta=0.02$ & 394,000 & 221 & 144 & 36.1 & 1.8 \\
Fractal segmentation $\beta=0.04$ & 607,000 & 274 & 58.4 & 32.1 & 38.0 \\
\hline
\end{tabular}

All numbers are per 10,000 years of simulated time

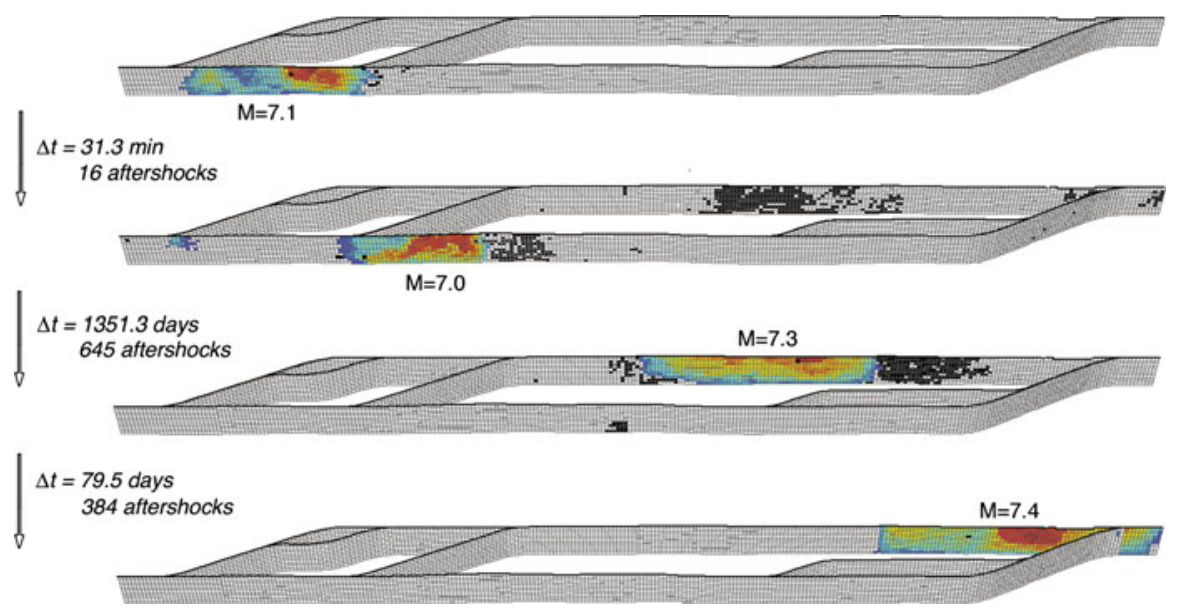

Figure 7

An example of a cluster of four large earthquakes occurring within a 4-year period. In each panel the colors indicate the amount of slip in one of the large earthquakes; the hypocenter of the large earthquake is marked in black; and, in addition, the hypocenters of all events taking place after the given large event (but before the subsequent large event) are also shown in black. The colorscale for slip runs from cool to hot colors for small to large values of slip, respectively. The maximum slip in the four large events is $4.3,3.3,4.9$, and $5.4 \mathrm{~m}$, in chronologic order.

section 4 must also involve a neighboring segment. Apparently, with increasing $\beta$ there is a progressive decoupling of slip across section boundaries that reduces frequency of large earthquakes on section 4 .

The regional differences in the distributions appear to be quite stable and independent of model details. Simulations with different combinations of model parameters were tested. These include reversing the sense of slip in the fault system from right lateral to left lateral, use of different element dimensions (1, 1.5, $3 \mathrm{~km})$ and different combinations of constitutive parameters. The distributions must be sensitive to earthquake stress drop, because larger stress drops will require greater elapsed time to recover stress-consequently the alternative model using a different set of constitutive parameters was designed to give the same average earthquake stress drop. The only one of these variations that produced substantial differences in the recurrence statistics was the most coarsely resolved model (patches with sidelengths of $3 \mathrm{~km}$ ). This model produced considerably longer average recurrence intervals for the largest $(M \geq 7)$ events. This dearth of large events is presumably due to the diffculties in propagating ruptures in such a model. As models with patches of sidelength $\leq 1.5 \mathrm{~km}$ agree with one another, we interpret the $3-\mathrm{km}$ patch size model to be too coarsely parameterized for our current purposes. Other than this one exception, we find that these various changes have only minor effects on the distributions that are comparable to the variations seen in Fig. 6.

An interesting feature of the fault system simulations is occasional clustering of large earthquake events. Clusters of large events, though relatively uncommon, are certainly a well-established characteristic of earthquake occurrence (KAGAN and JACKSON, 1991, 1999). With the idealized fault 
system, earthquakes $M \geq 7$ occur somewhere in the system at an average frequency of one every 3651 years, and most are isolated by four years or more from other large earthquakes. However, some large events occur as pairs, and even more rarely as triples (Table 1). Figure 7 shows an unusual set of four large events that propagate across much of the fault system. The intervals between large earthquakes in clusters vary from several seconds to 4 years, which is an arbitrary maximum interval used here in defining event clusters. The distribution of intervals between large events in clusters decays by Omori's law (with $p \sim 0.9$ ). In some cases the regions of slip in a cluster very slightly overlap. As shown in the example in Fig. 7, the subsequent large earthquake ruptures during particularly strong aftershock sequences, and the point of nucleation falls within this aftershock region.

\section{Summary and Discussion}

Earthquake nucleation with rate- and statedependent friction strongly affects the statistics of earthquake recurrence in the simulations, particularly at short time intervals and at smaller earthquake magnitudes. Density distributions of recurrence intervals have very narrow peaks at the shortest times (0-12 years) that consist of foreshocks, aftershocks, and earthquake clusters. Rates of recurrence within this peak decay by $t^{-0.8}$. Clustering in the form of large-earthquake pairs (and more rarely triples) is a consistent feature of the fault system simulations, but at low rates $(\sim 20 \%$ of $M \geq 7$ events are followed within 4 years by another such event). Intervals between large earthquake pairs vary from a few seconds to 4 years (our arbitrary cutoff to define large event clusters) and also follow an Omori decay, which is consistent with earthquake pairs in nature (KAGAN and JACKSON, 1991, 1999). From a regional earthquake hazard perspective the clusters represent a continuing interval of significantly increased hazard following large earthquakes. The follow-on events in large earthquake clusters initiate in the aftershock regions of the prior events and their occurrence correlates with especially high aftershock rates. There is little or no overlap of the areas of slip in the clusters.
The shapes of the recurrence distributions with isolated faults change with earthquake magnitude threshold $M_{\min }$ and form a narrow characteristic earthquake peak at high magnitudes. The characteristic earthquake peak occurs because earthquake ruptures that reach a critical size (about $10 \mathrm{~km}$ for faults that extend from the surface to $15 \mathrm{~km}$ ) have a strong tendency to continue to propagate to the limits of the model. The resulting end-to-end ruptures are highly periodic because the stress after the earthquakes is reset to a similar average state following each end-to-end rupture. Strong segmentation of faults reduces the periodicity and in the extreme eliminates end-to-end ruptures.

Recurrence distributions for individual fault sections within a fault system depend on magnitude and take great variety of forms that change with position within the fault system. In addition, the recurrence intervals have considerably wider distributions than isolated faults. The distributions appear to be quite insensitive to local details such as the addition of fault roughness. Limited tests that vary element dimensions and use different combinations of constitutive parameters reveal that the results are quite stable. These characteristics indicate that gross fault system geometry plays a primary role in establishing the characteristics of stress evolution that control earthquake recurrence. Above some limiting separation, fault step-overs form effective impediments to the propagation of earthquake ruptures and have a significant though lesser impact on the recurrence distributions.

One reason for undertaking this study was to begin to explore possible applications of earthquake simulations to assessments of regional earthquake probabilities. Current standard methodologies for assessing time-dependent earthquake probabilities employ models of regional seismicity that include information of past earthquakes (such as time and extent of earthquake slip) together with idealized probability density functions (PDFs) for the recurrence of earthquake slip. However, major sources of uncertainty in such assessments relate to both the choice of an appropriate functional form for a PDF and in specifying parameters for implementing the idealized PDF.

Questions surrounding current usage of generic PDFs in assessment of earthquake probabilities arise 
for a number of reasons. First, fundamentally different classes of PDFs based on Omori-type clustering, Poisson statistics, and quasi-periodicity individually capture well-established aspects of earthquake recurrence statistics, however no single distribution fully represents the range of observed behavior. For example, recent assessments of earthquake probabilities in California (e.g., Working GrouP ON California Earthquake Probabilities (WGCEP), 2007) used weighted estimates based on quasi-periodic and Poisson (exponential distribution) models of earthquake occurrence, which individually yield very different probabilities. Also, a number of uncertainties arise in implementing the generic PDFs because largely ad hoc assumptions must be made regarding relationships between stress accumulation and failure, characteristic earthquakes, probabilities of multisegment earthquakes, and magnitude-frequency statistics of large earthquakes on specific faults. Finally, the results of this study indicate that the distributions have significant magnitude and positional dependencies that are not considered in current approaches.

In place of idealized PDFs the use of empirical density distributions for probabilistic assessments could potentially address these shortcomings. An advantage of such an approach is that one would not be restricted to simple functional forms that cannot describe intrinsically complicated statistics, and most implementation and scaling issues relating to the use of PDFs are completely avoided. Also, magnitude dependencies and strong local variations in the recurrence distributions that are tied to fault system geometry (an observable) could be incorporated into probabilistic assessments. Ideally, one would like to use earthquake data for this purpose, however, long earthquake histories covering many average recurrence times of the largest events of interest are required to define local empirical distributionsclearly historic and paleoseismic data are inherently inadequate for this purpose.

Of necessity and design the simulations in this exploratory study are quite idealized. Certainly the practical use of fault system simulators in the assessment of time-dependent earthquake probabilities will require additional study. These include detailed region-specific simulations, and proper quantification of the effects of uncertain model parameters on the distributions. Our results demonstrate that gross fault system geometry strongly affects the shape of probability distributions for the recurrence of earthquake slip, and as a general rule the distributions are quite insensitive to small-scale geometric details. A possible exception may be sensitivity of the distributions to segmentation beyond some threshold in step-over distance. Because such features may be difficult to characterize at seismogenic depths, this effect may represent a significant source of uncertainty and merits close attention. In addition to time-dependent earthquake nucleation and the effect of fault system geometry in recurrence statistics investigated here, other model parameters will impact earthquake recurrence statistics. These include fault constitutive parameters, earthquake stress drop, and processes that produce stressing transients. A first-order dependence of mean recurrence time on fault slip rate and stress drop has been previously explored and characterized by WARD (1996) and RUNDLE $e$ t al. (2004). In our simulations, stress drop is controlled by fault normal stress and fault constitutive properties. Fault creep and viscoelastic relaxation following large earthquakes are widely documented and produce stressing rate transients that may impact recurrence statistics. Similarly, effective stress transients due to pore-fluid pressure changes could possibly affect recurrence statistics as well, though such effects have proven difficult to document. Though meriting further investigation, the effect of stress transients on earthquake occurrence appears to be at least partially mitigated by the ratestate nucleation process which is strongly self-driven, making nucleation times relatively insensitive to transient changes of stressing rates (DiETERICH, 1994).

Finally we note that with current standard methods, based on PDFs for earthquake recurrence intervals, the calculation of time-dependent probabilities using paleoseismic data and historical records of past earthquakes requires a number of interpretive and modeling steps that substantially increase uncertainties in ways that are difficult to quantify. Essentially, these steps convert very limited data on timing of an earthquake, and information on magnitude or amount of slip at a point on a fault, to a spatial 
(a) Slip in prior event $\geq 1 \mathrm{~m}, \quad \mathrm{M} 2 \geq 6.5$
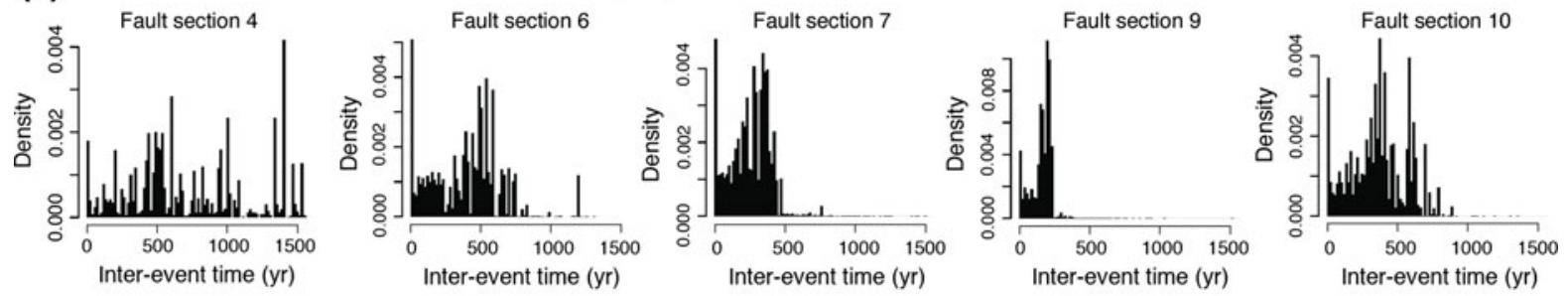

(b)
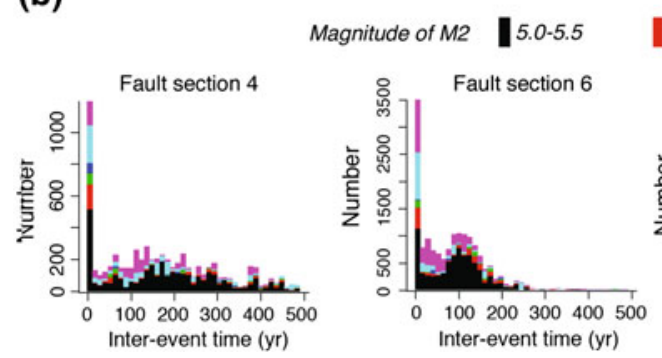

Prior event $\mathrm{M}_{1}=5.0-5.5, \quad \mathrm{M}_{2} \geq 5.0$
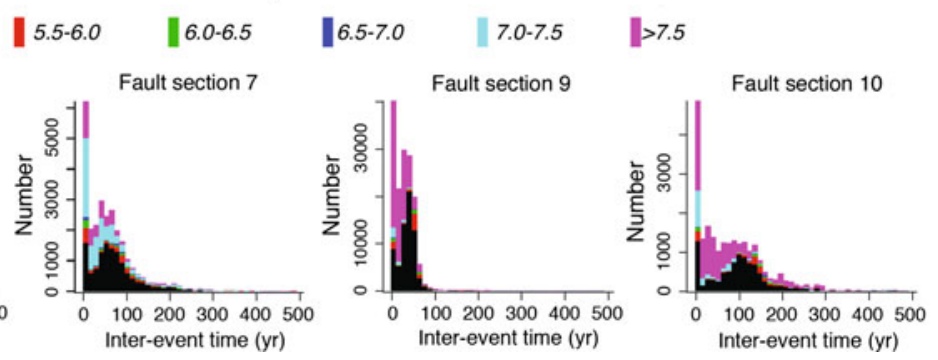

Figure 8

Examples of alternative parameterizations of density distributions of recurrence times. Data are from the smooth fault version of the fault system model of Figs. 5 and 6.

distribution of slip over an assigned section of fault. Simulations provide the capability to define specialized empirical density distributions that directly utilize primary observational data without the modeling steps and assumptions of current methods. Figure 8 illustrates two examples of alternative distributions. The first distribution (Fig. 8a) is defined in terms of magnitude of slip at an observation point in the prior earthquake. It is intended to directly utilize paleoseismic data on the amount of slip in the prior earthquake at some point on a fault, with no other direct information on earthquake magnitude or extent of slip. The second distribution (Fig. 8b) is intended to represent a case in which the time and magnitude (with some uncertainty) of the prior earthquake are both known. The distribution provides information about both the time of the following event and also its magnitude. Both distributions relax the assumptions of characteristic earthquakes and allow for earthquakes of varying sizes.

The results in Fig. $8 \mathrm{~b}$ are rather interesting. Broad quasi-periodic peaks for earthquakes M5-M5.5 following an earthquake M5-M5.5 are quite evident in these distributions, but the sub-distributions for $M \geq 7.5$ following a M5.5 earthquake decay monotonically and roughly follow an exponential distribution indicating a constant Poisson rate of occurrence following a M5.5 event. Some other examples of specialized density distributions that might be assembled directly from the synthetic catalogs include (a) situations in which historical records indicate the prior earthquake may lie within a region although causative fault is uncertain, (b) recurrence of slip exceeding some amount at a specific site, in some time interval (of possible interest for lifelines that cross faults), and (c) probability of future earthquake by time and distance from a site.

\section{Acknowledgements}

We thank Euan Smith and two anonymous reviewers for comments which improved the manuscript. Funding for this work was provided by grants from the USGS (\#G09AP00009), and the Southern California Earthquake Center (SCEC\#08092). SCEC is funded by NSF Cooperative Agreement EAR-0529922 and USGS Cooperative Agreement 07HQAG0008. The SCEC contribution number for this paper is 1273 . 
Open Access This article is distributed under the terms of the Creative Commons Attribution Noncommercial License which permits any noncommercial use, distribution, and reproduction in any medium, provided the original author(s) and source are credited.

\section{REFERENCES}

Belardinelli, M. E., Bizzarri A., and Cocco, M. (2003), Earthquake triggering by static and dynamic stress changes. J. Geophys. Res. (Solid Earth) 108, 2135士, doi:10.1029/ 2002JB001779.

Ben-Zion, Y. and Rice, J. R. (1997), Dynamic simulations of slip on a smooth fault in an elastic solid. J. Geophys. Res. 102, 1777117784, doi:10.1029/97JB01341.

Ben-Zion, Y., and SAmmis, C. G. (2003), Characterization of fault zones, Pure App. Geophy. 160, 677-715

Beroza, G. C., and Mikumo, T. (1996), Short slip duration in dynamic rupture in the presence of heterogeneous fault properties, J. Geophys. Res. 101, 22449-22460, doi:10.1029/ 96JB02291.

Bonnet, E., Bour, O., Odling, N. E., Davy, P., Main, I., Cowie, P., and Berkowitz, B. (2001), Scaling of fracture systems in geological media. Rev. Geophys. 39, 347-384, doi:10.1029/ 1999RG000074.

BRUNE, J. (1970), Tectonic stress and the spectra of seismic shear waves from earthquakes. J. Geophys. Res. 75(26), 4997-5009.

Chester, F. M., and Chester, J. S. (2000), Stress and deformation along wavy frictional faults. J. Geophys. Res. 105, 23,42123,430, doi:10.1029/2000JB900241.

Dieterich, J. (1981), Constitutive properties of faults with simulated gouge. In Carter, N. L., Friedman, M., Logan, J.M., and Sterns, D. W. (eds), Monograph 24, Mechanical behavior of crustal rocks, Am. Geophys. Union, Washington, D.C., pp. 103120.

DiETERICH, J. (1987) Nucleation and triggering of earthquake slip: effect of periodic stresses. Tectonophysics 144, 127-139, doi: 10.1016/0040-1951(87)90012-6.

DieTERICH, J., Applications of rate-and-state-dependent friction to models of fault slip and earthquake occurrence. In SCHUBERT, G. (ed.) Treatise on Geophysics, Vol. 4 (Elsevier, Oxford 2007).

Dieterich, J., and SMith, D. (2009), Non-planar faults: mechanics of slip and off-fault damage, Pure Appl. Geophys., 166, 17991815.

DiETERICH, J.H. (1979), Modeling of rock friction 1. Experimental results and constitutive equations. J. Geophys. Res. 84, 21612168.

DiETERICH, J. H. (1992), Earthquake nucleation on faults with rateand state-dependent strength. Tectonophysics 211, 115-134.

DieTERICH, J. H. (1994), A constitutive law for rate of earthquake production and its application to earthquake clustering, J. Geophys. Res. 99, 2601-2618.

Dieterich, J. H. (1995), Earthquake simulations with time-dependent nucleation and long-range interactions. J. Nonlinear Proc. Geophys. 2, 109-120.

Dieterich, J. H., and Kilgore, B. (1996) Implications of Fault Constitutive Properties for Earthquake Prediction. Proc. Natl. Acad Sci. USA 93, 3787-3794.
DuAn, B. and Oglesby, D.D. (2006), Heterogeneous fault stresses from previous earthquakes and the effect on dynamics of parallel

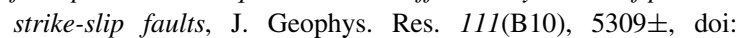
10.1029/2005JB004138.

Fliss, S., Вhat, H. S., Dmowska, R., Rice, J. R. (2005), Fault branching and rupture directivity. J. Geophys. Res. 110(B9), 6312 士, doi:10.1029/2004JB003368.

Fournier, A., Fussell, D., and CARpenter, L. (1982), Computer rendering of stochastic models, Commun. ACM 25(6), 371-384, doi: $10.1145 / 358523.358553$.

Gomberg, J., Blanpied, M. L., and Beeler, N. M. (1997), Transient triggering of near and distant earthquakes, Bull. Seismol. Soc. Am. 87(2), 294-309, http://www.bssaonline.org/cgi/content /abstract/87/2/294, http://www.bssaonline.org/cgi/reprint/87/2/ 294.pd.

Gomberg, J., Beeler, N.M., Blanpied, M.L., and Bodin, P. (1998), Earthquake triggering by transient and static deformations, J. Geophys. Res. 103, 24411-24426, doi:10.1029/98JB01125.

Gomberg, J., BeEler, N., and Blanpied, M. (2000), On rate-state and Coulomb failure models, J. Geophys. Res. 105, 7857-7872, doi:10.1029/1999JB900438.

Harris, R. A., Archuleta, R. J., Day, S. M. (1991) Fault steps and the dynamic rupture process: 2-D numerical simulations of a spontaneously propagating shear fracture, Geophys. Res. Lett. 18, 893-896.

Heaton, T.H. (1990), Evidence for and implications of self-healing pulses of slip in earthquake rupture, Phys. Earth Planet. Inter. 64, 1-20, doi:10.1016/0031-9201(90)90002-F.

KAGAN, Y. Y., and JACKSON, D. D. (1991), Long-term earthquake clustering, Geophys. J. Int. 104(1), 117-134, doi:10.1111/j.1365246X.1991.tb02498.x.

KAGAN, Y. Y., and JACKSON, D. D. (1999), Worldwide doublets of large shallow earthquakes, Bull. Seismol. Soc. Am. 89(5), 11471155.

KInG, G. C. P., and Bowman, D. D. (2003), The evolution of regional seismicity between large earthquakes, J. Geophys. Res. 108, 2096士, doi:10.1029/2001JB000783.

Linker, M. F., and Dieterich, J. H. (1992), Effects of variable normal stress on rock friction-observations and constitutive equations, J. Geophys. Res. 97, 4923-4940.

MARONE, C. (1998), Laboratory-derived friction laws and their application to seismic faulting. Annual Rev. Earth Planet. Sci. 26, 643-696, doi:10.1146/annurev.earth.26.1.643.

Meade, B. J. (2007), Algorithms for the calculation of exact displacements, strains, and stresses for triangular dislocation elements in a uniform elastic half space, Comp. Geosci. 33, 1064-1075, doi:10.1016/j.cageo.2006.12.003.

Nielsen, S. B., and Knopoff, L. (1998), The equivalent strength of geometrical barriers to earthquakes, J. Geophys. Res. 103, 9953-9966, doi:10.1029/97JB03293.

Oglesby, D. D., Day, S. M., Li, Y. G., Vidale, J. E. (2003), The 1999 Hector Mine earthquake: the dynamics of a branched fault system, Bull. Seismol. Soc. Am. 93, 2459-2476

ОкADA, Y. (1992), Internal deformation due to shear and tensile faults in a half-space, Bull. Seismol. Soc. Am. 82, 1018-1040.

Окиво, Р. G., and Акг, К. (1987), Fractal geometry in the San Andreas fault system, J. Geophys. Res. 92, 345-356.

Power, W. L., and Tullis, T. E. (1991), Euclidean and fractal models for the description of rock surface roughness, J. Geophys. Res. 96, 415-424. 
Rice, J. R. (1983), Constitutive relations for fault slip and earthquake instabilities, Pure Appl. Geophys. 121, 443-475, doi: 10.1007/BF02590151.

Robinson, R., and BENITES, R. (1995) Synthetic seismicity models of multiple interacting faults, J. Geophys. Res. 100, 18229-18238, doi:10.1029/95JB01569.

RUBin, A. M., and AMPUERo, J. P. (2005), Earthquake nucleation on (aging) rate and state faults. J. Geophys. Res. (Solid Earth) 110(B9), 11312士, doi:10.1029/2005JB003686.

Ruina, A. (1983), Slip instability and state variable friction laws, J. Geophys. Res. 88, 10359-10370.

Rundle, J. B., and Klein, W. (1993), Scaling and critical phenomena in a cellular automaton slider-block model for earthquakes. J. Statist. Phys. 72, 405-412, doi:10.1007/ BF01048056.

Rundle, J. B., Rundle, P. B., Donnellan, A., and Fox, G. (2004), Gutenberg-Richter statistics in topologically realistic systemlevel earthquake stress-evolution simulations, Earth, Planets, and Space 56, 761-771.

Sagy, A., Brodsky, E. E., and Axen, G. J. (2007), Evolution of fault-surface roughness with slip, Geology 35, 283土, doi: 10.1130/G23235A.1.

SAucier, F., Humphreys, E., and Weldon, R. I. (1992), Stress near geometrically complex strike-slip faults - Application to the San Andreas fault at Cajon Pass, southern California, J. Geophys. Res. 97, 5081-5094.

SAVAGE, J. C. (1983), A dislocation model of strain accumulation and release at a subduction zone. J. Geophys. Res. 88, 49844996.

Scholz, C. H. and Aviles, C. A. (1986), The fractal geometry of faults and faulting. In Das S., Boatwright J., Scholz C. H. (eds), Earthquake source mechanics (Maurice Ewing Volume 6), Am. Geophys. Union, Washington, D.C., pp. 147-155.

Shaw, B. E. and Dieterich, J. H. (2007), Probabilities for jumping fault segment stepovers, Geophys. Res. Lett. 34:L01,307, doi: 10.1029/2006GL027980.
Steacy, S. J. and McCloskey, J. (1999), Heterogeneity and the earthquake magnitude-frequency distribution. Geophys. Res. Lett. 26, 899-902, doi:10.1029/1999GL900135.

Stirling, M. W., Wesnousky, S. G., and Shimazaki, K. (1996), Fault trace complexity, cumulative slip, and the shape of the magnitude-frequency distribution for strike-slip faults: a global survey, Geophys. J. Internatl. 124, 833-868, doi:10.1111/j. 1365-246X.1996.tb05641.x.

TulLis, T. E. (1988), Rock friction constitutive behavior from laboratory experiments and its implications for an earthquake prediction field monitoring program, Pure Appl. Geophys. 126, 555-588, doi:10.1007/BF00879010.

WARD, S. N. (1996), A synthetic seismicity model for southern California: Cycles, probabilities, and hazard, J. Geophys. Res. 101, 22393-22418, doi:10.1029/96JB02116.

WARD, S. N. (2000), San Francisco Bay Area earthquake simulations: A step toward a standard physical earthquake model, Bull. Seismol. Soc. Am. 90, 370-386, doi:10.1785/0119990026.

WeSNOUSKY, S. G. (1994), The Gutenberg-Richter or characteristic earthquake distribution, which is it? Bull. Seismol. Soc. Am. 84(6), 1940-1959, http://www.bssaonline.org/cgi/content/ abstract/84/6/1940, http://www.bssaonline.org/cgi/reprint/84/6/ 1940.pd.

Working Group on California Earthquake Probabilities (WGCEP) (2007), The Uniform California Earthquake Rupture Forecast, version 2 (UCERF 2). USGS Prof. Pap. 2007-1437, http://pubs.usgs.gov/of/2007/143.

ZHENG, G. and RicE, J. R. (1998), Conditions under which velocityweakening friction allows a self-healing versus a cracklike mode of rupture, Bull. Seismol. Soc. Am. 86, 1466-1483.

Ziv, A. and Rubin, A. M. (2003), Implications of rate-and-state friction for properties of aftershock sequence: Quasi-static inherently discrete simulations, J. Geophys. Res. 108, 2051, doi:10.1029/2001JB001219. 